\title{
Eosinophils: a new player in coronary atherosclerotic disease
}

\author{
Giampaolo Niccoli and Nicola Cosentino
}

Hypertension Research (2012) 35, 269-271; doi:10.1038/hr.2011.221; published online 19 January 2012

$\mathrm{T}$

he association between vascular calcification and vascular disease has been known to anatomists and pathologists for several hundred years. Radiological detection of coronary artery calcification (CAC) in vivo by fluoroscopy was described in the late $1950 \mathrm{~s},{ }^{1}$ and an association between the presence of CAC and the risk of cardiovascular events was subsequently demonstrated. ${ }^{2}$ It is now widely accepted that the presence of calcium in coronary arteries is pathognomonic of atherosclerosis, ${ }^{3}$ and a close correlation between the atherosclerotic plaque burden and the extent of CAC has been confirmed both by histopathology and intravascular ultrasound, with the total CAC score representing an anatomic measure of overall coronary plaque burden. ${ }^{4,5}$

In this context, there has been an exponential increase in interest in cardiac computed tomography as applications expanded from the identification of CAC to noninvasive coronary angiography, through obtaining cross-sectional images of the heart in subsecond scanning times and accurately detecting and quantifying even small areas of CAC. ${ }^{6}$

Among inflammatory cells, leukocyte recruitment and the expression of proinflammatory cytokines related to leukocyte activation have been shown to characterize all steps of atherothrombosis. ${ }^{7}$ The leukocyte count has been correlated with coronary atherosclerosis disease since the 1920 s. $^{8}$ Over the last several decades, an increasing number of epidemiological and clinical studies have shown leukocytes to be an independent predictor of future cardiovascular events, both in healthy individuals free of coronary artery

Dr G Niccoli and N Cosentino are at the Istituto di Cardiologia, Università Cattolica del Sacro Cuore, L.go A. Gemelli, 8 Roma, Italy.

E-mail: gniccoli73@hotmail.it disease at baseline and in patients with stable angina, unstable angina, or a history of myocardial infarction. ${ }^{9}$ Among differential leukocyte counts, recent observations suggest that eosinophils may have a role in coronary atherosclerosis. Indeed, prospective studies have consistently shown an association between eosinophil count and increased risk for future cardiovascular events. ${ }^{9}$

The association between eosinophils and coronary calcium has not been tested until now. In this issue of Hypertension Research, Tanaka $\mathrm{M}$ et al. ${ }^{10}$ showed the role of eosinophils in a cross-sectional study of 1363 consecutive participants with a clinical suspicion of coronary heart disease, with the aim of evaluating the relationships between the CAC score determined by multislice computed tomography and the peripheral eosinophil count, as well as major cardiovascular risk factors. They found a positive correlation between $\log (\mathrm{CAC}+1)$ and the eosinophil count ( $r=0.165, P<0.0001)$. Of note, eosinophil count quartiles were significantly associated with $\log (\mathrm{CAC}+1)(P<0.0001)$, and the highest eosinophil count quartile had a higher $\log (\mathrm{CAC}+1)$ than the lowest $(P<0.0001)$ and second $(P=0.0001)$ eosinophil count quartiles. Moreover, the eosinophil count was associated with significant stenosis, defined as any arterial stenosis that produced more than $50 \%$ luminal narrowing $(P=0.0034)$. Finally, using multivariate linear regression analysis, the eosinophil count $(\beta=0.147, \quad P=0.001)$ was an independent determinant of $\log (\mathrm{CAC}+1)$.

In the Hiroshima and Nagasaki Adult Health Study, ${ }^{11}$ the total leukocyte count correlated positively with the incidence of coronary artery disease in a large population of individuals free of disease at baseline. When differential cell counts were considered, a correlation was found between a moderately elevated eosinophil count and an increased risk of disease, as well as between neutrophil, eosinophil and monocyte (but not lymphocyte) counts and the incidence of disease. Other evidence comes from a study by Erdogan et al., ${ }^{12}$ in which the authors were able to find elevated levels of serum immunoglobulin E, basophils and eosinophils in coronary artery disease patients compared with healthy control subjects. Finally, Niccoli et al. ${ }^{13}$ recently showed that eosinophil cationic protein (ECP), a sensitive marker of eosinophil activation, is associated with coronary atherosclerosis and, when added to the main cardiovascular risk factors, improves the classification performance for the diagnosis of angiographically detectable coronary atherosclerosis among patients undergoing coronary angiography because of chest pain.

The involvement of eosinophils in coronary atherosclerosis disease has been also suggested by other observations. Eotaxin, an eosinophil-specific chemoattractant, is overexpressed in human atherosclerotic lesions, ${ }^{14}$ and patients with coronary artery disease show higher circulating levels of eotaxin than healthy controls. ${ }^{15,16}$ Accordingly, a nonconservative polymorphism in the eotaxin gene $^{17}$ and sequence variants affecting the eosinophil count ${ }^{18}$ have recently been associated with an increased risk of myocardial infarction.

Eosinophils may mediate their pro-atherosclerotic actions through proteins stored in prominent cytoplasmic granules. ${ }^{19}$ In particular, preformed basic proteins, such as eosinophil peroxidase, eosinophil-derived neurotoxin, major basic protein and ECP are the main components of granules. ${ }^{19}$ In addition, the secretory granules of eosinophils contain preformed cytokines, such as granulocyte-macrophage colony-stimulating factor, interleukin (IL)-3, IL-4, IL-5, IL-6, 


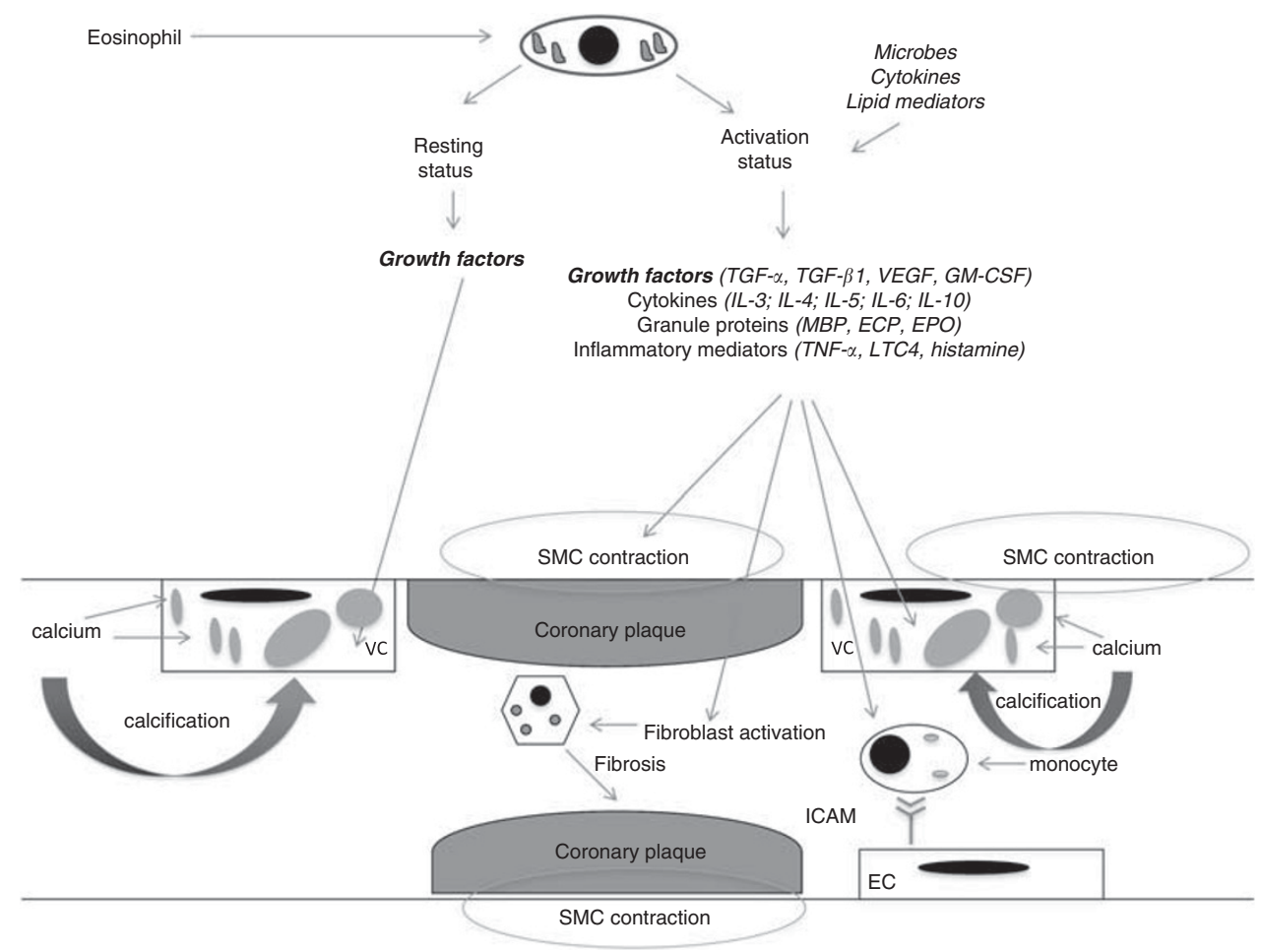

Figure 1 The storage, production and release of various molecules by eosinophils may affect tissue development, damage, repair and homeostasis, may regulate immune responses and exert proinflammatory effector functions. In particular, low-grade production of growth factor by eosinophils in the resting status is believed to contribute to vascular calcification, by stimulating calcium overload inside vascular cells. Finally, when activated, eosinophils may further stimulate calcium overload, smooth muscle cell contraction, fibroblast activation and monocyte adhesion to endothelial cells, which contribute to coronary atherosclerosis formation, progression and calcification. EC, endothelial cell; ECP, eosinophil cationic protein; EPO, eosinophil peroxidase; GM-CSF, granulocyte-macrophage colony-stimulating factor; ICAM, inter-cellular adhesion molecule; IL, interleukin; LTC4, leukotrienes C4; MBP, major basic protein; SMC, smooth muscle cell contraction; TGF- $\alpha$, transforming growth factor- $\alpha$; TGF- $\beta 1$, transforming growth factor- $\beta 1$; VC, vascular cells; VEGF, vascular endothelial growth factor. A full color version of this figure is available at the Hypertension Research journal online.

IL-10, transforming growth factor-beta and tumor necrosis factor-alpha, ${ }^{19}$ which may modulate the acute phase response and innate inflammatory response. ${ }^{20}$ Some of the eosinophil mediators, such as transforming growth factor-beta, IL-4, IL-6, tumor necrosis factor-alpha, ECP and major basic protein can be fibrogenic. ${ }^{21}$ Interestingly, of these factors, transforming growth factor-beta has been reported to enhance in vitro calcification of vascular cells. ${ }^{22}$ Finally, eosinophils synthesize and release bioactive mediators, such as leukotriene $\mathrm{C} 4$, a potent stimulant of vasoactivity and smooth muscle contraction, and they can induce the release of a number of vasoactive substances, including histamine, prostaglandin D2 and leukotrienes C4 and D4, from mast cells and basophils. ${ }^{19}$

Interestingly, eosinophil activation can be monitored by using serum biomarkers, among which ECP, a zinc-containing, highly cationic protein that is stored in peroxidasepositive and negative eosinophil granules, stands out. ${ }^{23}$ Of note, ECP was found to upregulate inter-cellular adhesion molecule1 expression on endothelial cells, ${ }^{24}$ allowing monocyte adhesion to the endothelium.
Moreover, ECP has a number of modulating activities in vitro, including the inhibition of proliferative T-lymphocyte responses to antigen, the inhibition of immunoglobulin synthesis and the modulation of fibroblast activity. ${ }^{25}$ Thus, studies aiming at assessing the diagnostic and prognostic role of eosinophil activation, along with the eosinophil count, should be performed in order to shed more light on these small but potent cells in the setting of coronary atherosclerosis disease (Figure 1).

Accurate risk assessment of patients with suspected coronary artery disease may be helpful in decreasing cardiovascular events through more appropriate targeting of preventive measures. Hence, researchers have turned their attention to noninvasive modalities, such as coronary computed tomography, that are able to image the atherosclerotic plaque in its preclinical stages. The measurement of CAC in patients has emerged as a quantitative marker of coronary artery atherosclerosis severity, and greater calcium burdens correlate with more advanced disease. By contrast, circulating biomarkers may have an additive diagnostic and prognostic utility above that conferred by imaging modalities.

As eosinophils seem to have a role in coronary artery disease independently of known risk factors or other inflammatory cell types, they could be a target of new, specific therapies aimed at preventing eosinophil-mediated coronary artery disease formation, progression and calcification.

1 Blankenhorn DH, Stern D. Calcification of the coronary arteries. Am J Roentgenol Radium Ther Nucl Med 1959; 81: 772-777.

2 Margolis JR, Chen JT, Kong Y, Peter RH, Behar VS, Kisslo JA. The diagnostic and prognostic significance of coronary artery calcification. A report of 800 cases. Radiology 1980; 137: 609-616.

3 Budoff MJ, Achenbach S, Blumenthal RS, Carr JJ, Goldin JG, Greenland P, Guerci AD, Lima JA, Rader DJ, Rubin GD, Shaw LJ, Wiegers SE. Assessment of coronary artery disease by cardiac computed tomography: a scientific statement from the American Heart Association Committee on Cardiovascular Imaging and Intervention, Council on Cardiovascular Radiology and Intervention, and Committee on Cardiac Imaging, Council on Clinical Cardiology. Circulation 2006; 114: 1761-1791.

4 Mintz GS, Pichard AD, Popma JJ, Kent KM, Satler LF, Bucher TA, Leon MB. Determinants and correlates of target lesion calcium in coronary artery disease: a 
clinical, angiographic and intravascular ultrasound study. J Am Coll Cardiol 1997; 29: 268-274.

5 Baumgart D, Schmermund A, Goerge G, Haude M, Ge J, Adamzik M, Sehnert C, Altmaier K, Groenemeyer $D$, Seibel R, Erbel R. Comparison of electron beam computed tomography with intracoronary ultrasound and coronary angiography for detection of coronary atherosclerosis. J Am Coll Cardiol 1997; 30 . 57-64.

6 Fiorino AS. Electron-beam computed tomography, coronary artery calcium, and evaluation of patients with coronary artery disease. Ann Intern Med 1998; 128 839-847.

7 Libby P, Theroux P. Pathophysiology of coronary artery disease. Circulation 2005; 111: 3481-3488.

8 Keefer CS, Resnik WH. Angina pectoris: a syndrome caused by anoxemia of the myocardium. Arch Intern Med 1928; 41: 769-807.

9 Madjid M, Awan I, Willerson JT, Casscells SW. Leukocyte count and coronary heart disease: implications for risk assessment. J Am Coll Cardiol 2004; 44: 1945-1956.

10 Tanaka M, Fukui M, Tomiyasu K, Akabame S, Nakano K, Yamasaki M, Hasegawa G, Oda Y, Nakamura N. Eosinophil count is positively correlated with coronary artery calcification Hypertens Res 2012; 35 325-328.

11 Prentice RL, Szatrowski TP, Fujikura T, Kato H, Mason MW, Hamilton HH, Prentice RL. Leukocyte counts and coronary heart disease in a Japanese cohort. $A m ~ J$ Epidemiol 1982; 116: 496-509.

12 Erdogan O, Gul C, Altun A, Ozbay G. Increased immunoglobulin $E$ response in acute coronary syndromes. Angiology 2003; 54: 73-79.

13 Niccoli G, Ferrante G, Cosentino N, Conte M, Belloni F, Marino M, Bacà M, Montone RA, Sabato V, Schiavino D, Patriarca G, Crea F. Eosinophil cationic protein: a new biomarker of coronary atherosclerosis. Atherosclerosis 2010; 211: 606-611.

14 Haley KJ, Lilly CM, Yang JH, Feng Y, Kennedy SP, Turi TG, Thompson JF, Sukhova GH, Libby P, Lee RT. Overexpression of eotaxin and the CCR3 receptor in human atherosclerosis: using genomic technology to identify a potential novel pathway of vascular inflammation. Circulation 2000; 102: 2185-2189.

15 Economou E, Tousoulis D, Katinioti A, Stefanadis C, Trikas A, Pitsavos C, Tentolouris C, Toutouza MG, Toutouzas $P$. Chemokines in patients with ischaemic heart disease and the effect of coronary angioplasty. Int J Cardiol 2001; 80: 55-60.

16 Emanuele E, Falcone C, D’Angelo A, Minoretti P, Buzzi MP, Bertona M, Geroldi D. Association of plasma eotaxin levels with the presence and extent of angiographic coronary artery disease. Atherosclerosis 2006; 186: $140-145$.

17 Zee RY, Cook NR, Cheng S, Erlich HA, Lindpaintner K, Lee RT, Ridker PM. Threonine for alanine substitution in the eotaxin (CCL11) gene and the risk of incident myocardial infarction. Atherosclerosis 2004; 175: 91-94.

18 Gudbjartsson DF, Bjornsdottir US, Halapi E, Helgadottir A, Sulem P, Jonsdottir GM, Thorleifsson G, Helgadottir $\mathrm{H}$, Steinthorsdottir V, Stefansson H, Williams C, Hui J, Beilby J, Warrington NM, James A, Palmer LJ, Koppelman $G H$, Heinzmann $A$, Krueger $M$, Boezen HM, Wheatley A, Altmuller J, Shin HD, Uh ST, Cheong HS, Jonsdottir B, Gislason D, Park CS, Rasmussen LM, Porsbjerg C, Hansen JW, Backer V, Werge T, Janson C, Jönsson UB, Ng MC, Chan J, So WY, Ma R, Shah SH, Granger CB, Quyyumi AA, Levey AI, Vaccarino V, Reilly MP, Rader DJ, Williams MJ, van Rij AM, Jones GT, Trabetti E, Malerba G, Pignatti PF, Boner A, Pescollderungg $L$, Girelli D, Olivieri O, Martinelli N, Ludviksson BR, Ludviksdottir D, Eyjolfsson GI, Arnar D, Thorgeirs- son G, Deichmann K, Thompson PJ, Wjst M, Hall IP, Postma DS, Gislason T, Gulcher J, Kong A, Jonsdottir I, Thorsteinsdottir U, Stefansson K. Sequence variants affecting eosinophil numbers associate with asthma and myocardial infarction. Nat Genet 2009; 41: 342-347.

19 Kita H. Eosinophils: multifaceted biological properties and roles in health and disease. Immunol Rev 2011; 242: 161-177.

20 Serhan CN, Savill J. Resolution of inflammation: the beginning programs the end. Nat Immunol 2005; 6 : 1191-1197.

21 Levi-Schaffer F, Garbuzenko E, Rubin A, Reich R, Pickholz D, Gillery P, Emonard H, Nagler A, Maquart FA. Human eosinophils regulate human lung- and skinderived fibroblast properties in vitro: a role for transforming growth factor beta (TGF-beta). Proc Natl Acad Sci USA 1999; 96: 9660-9665.

22 Watson KE, Boström K, Ravindranath R, Lam T, Norton B, Demer LL. TGF-beta 1 and 25-hydroxycholesterol stimulate osteoblast-like vascular cells to calcify. J Clin Invest 1994; 93: 2106-2113.

23 Venge P, Byström J, Carlson M, Hâkansson L, Karawacjzyk M, Peterson C, Sevéus L, Trulson A. Eosinophil cationic protein (ECP): molecular and biological properties and the use of ECP as a marker of eosinophil activation in disease. Clin Exp Allergy 1999; 29: 1172-1186.

24 Chihara J, Yamamoto T, Kurachi D, Kakazu T, Higashimoto I, Nakajima S. Possible release of eosinophil granule proteins in response to signaling from intercellular adhesion molecule-1 and its ligands. Int Arch Allergy Immunol 1995; 108(Suppl 1): 52-54.

25 Hernnäs J, Särnstrand B, Lindroth P, Peterson CG, Venge $P$, Malmström A. Eosinophil cationic protein alters proteoglycan metabolism in human lung fibroblast cultures. Eur J Cell Biol 1992; 59: 352-363. 